\title{
Effects of Tire Pressure on Biceps Brachii and Triceps Brachii Activity When Operating a Manual Wheelchair
}

\author{
Sang-Yeol Lee, PT, PhD • Su-Kyoung Lee, PT, PhD ${ }^{1 \dagger}$ \\ Department of Physical Therapy, Kyungsung University \\ ${ }^{1}$ Department of Physical Therapy, DongEui University
}

Received: May 20, 2016 / Revised: May 20, 2016 / Accepted: June 17, 2016

(C) 2016 J Korean Soc Phys Med

\begin{abstract}
| Abstract |
PURPOSE: This study was measured the differences in the flexor and extensor muscle activities of the elbow joints based on the tire pressure of wheelchairs during propulsion, investigating the optimal tire pressure for improving occupants' propulsion and avoiding related injury.
\end{abstract}

METHODS: Ten healthy volunteers (10 men aged $23.1 \pm$ 1.9 years, weight: $67.9 \pm 3.4 \mathrm{~kg}$, height: $175.1 \pm 2.7 \mathrm{~cm}$ ) took part in the study. The mean values used in the statistical process were obtained from values measured while a subject sitting on a wheelchair propelled himself forward for 10 meters on a flat floor at maximum speed. The tire pressure of the wheelchairs was set at $100 \mathrm{psi}, 50 \mathrm{psi}$, and $25 \mathrm{psi}$. All of the subjects performed wheelchair propulsion for each pressure. This study was measured the activation of the biceps brachii and triceps brachii muscles on the dominant side during wheelchair propulsion. The measured data was analyzed using one-way analysis of variance (ANOVA) via the statistical package for the social sciences (SPSS) version

†Corresponding Author : ptlsk@deu.ac.kr

This is an Open Access article distributed under the terms of the Creative Commons Attribution Non-Commercial License (http://creativecommons.org/licenses/by-nc/3.0) which permits unrestricted non-commercial use, distribution, and reproduction in any medium, provided the original work is properly cited.
12.0 for Windows to compare the muscle activity.

RESULTS: The muscle activities of the biceps brachii and triceps brachii were significant differences between each pressure group. The post hoc test found statistically significant differences between $100 \mathrm{psi}$ and $50 \mathrm{psi}$ and $100 \mathrm{psi}$ and $25 \mathrm{psi}$ for the biceps brachii and triceps brachii muscles, respectively.

CONCLUSION: The maintaining proper tire pressure in a wheelchair may help to prevent overuse syndrome in the occupant's elbow joints.

Key Words: Propulsion, Muscle activity, Wheelchair tire pressure

\section{Introduction}

Wheelchairs are the most common means of transport for patients who have difficulty walking independently. A wheelchair's tires are the only part of the device that makes contact with the ground, and they fully support the occupant's weight (Booka et al., 2015). For cars, tire type affects stability and efficiency (as indicators of stabilization and efficiency, respectively). Even the same type of tire can influence mileage and braking distance differently because its friction area on the ground varies based on 
tire pressure (Thomas et al., 2014; Hong and Lee, 2010). Tire pressure exercises an absolute effect on vehicles' energy consumption and safety. While cars gain momentum as they consume fuel, the manual wheelchair's occupant propels it, using his or her muscles to generate power while turning the wheels (Chow et al., 2001). Because the occupant directly provides the propulsion, the tire pressure may negatively affect his or her energy consumption and heart rate if it falls to 50 psi or below (Sawatzky et al., 2005). It can be said that a wheelchair's tire pressure significantly affects the propulsion of a manual wheelchair (de Groot et al., 2013).

A manual wheelchair is propelled by movements of the shoulders, elbows, wrist joints, and torso. Most wheelchair users suffer from musculoskeletal disorders such as tendonitis due to excessive use of their elbow joints (Monahan et al., 1986).

This study measured the differences in the flexor and extensor muscle activities of the elbow joints based on the tire pressure of wheelchairs during propulsion, investigating the optimal tire pressure for improving occupants' propulsion and avoiding related injury.

\section{Methods}

\section{Participants}

Ten healthy volunteers (10 men aged $23.1 \pm 1.9$ years; age range: 20-26 years; weight: $67.9 \pm 3.4 \mathrm{~kg}$; weight range: $62-74 \mathrm{~kg}$; height: $175.1 \pm 2.7 \mathrm{~cm}$; height range: 171-179 $\mathrm{cm})$ took part in the study. When selecting the participants, those with malformation or neurological disease in the lower limb and upper limb joints in the past or at the present time were excluded. All the subjects voluntarily participated in this study and signed an agreement on this experiment that contained that they were able to reject participation anytime if they wanted. The experimenter sufficiently explained experimental procedures and cautions prior to the experiment. All of the subjects gave their written informed consent, and the researchers' institutional review board approved the study.

\section{Procedure}

The mean values used in the statistical process were obtained from values measured while a subject sitting on a wheelchair propelled himself forward for $10 \mathrm{~m}$ on a flat floor at maximum speed. The standard wheelchair type with the pneumatic tire (Primo v-track $24 \times 13 / 8$-inch tire, Primo, USA) was used for this study. The height of the wheelchair seat was fixed when a subject sat on the wheelchair with his elbow joints bent at 90 degrees (Lee et al., 2012; Lee, 2009) The floor was made of marble. The tire pressure of the wheelchairs was set at $100 \mathrm{psi}$, $50 \mathrm{psi}$, and 25 psi. These pressures were reported as displaying differences in energy consumption in other studies. All of the subjects performed wheelchair propulsion for each pressure (Sawatzky et al., 2005).

Surface electromyography (EMG) (MyoSystem TM DTS, Noraxon Inc., USA) was used featuring a surface electrode (IWC-DTS and 9113A-DTS, Noraxon Inc., USA) consisting of three electrodes (Positive-Ground-Negative) to measure the activation of the biceps brachii and triceps brachii muscles on the dominant side. The surface electrode was attached in accordance with the surface electromyography for the non-invasive assessment of muscles (SENIAM). The frequency of the EMG signal was set to $20-500 \mathrm{~Hz}$ the sampling frequency was $1,024 \mathrm{~Hz}$. Depilation was performed using a razor on the attaching sites; any remaining hair was removed with sandpaper. The level of muscle activation during exercise was expressed as \% MVIC by calculating the relative muscle contraction of the $100 \%$ maximal voluntary isometric contraction. Five seconds maximal voluntary isometric contraction of biceps brachii was collected during a sitting isometric maximal elbow flexion on elbow 90 degree flexion position and triceps brachii was collected during a sitting isometric maximal elbow extension on same position. 


\section{Data analysis}

The measured data was analyzed using one-way analysis of variance (ANOVA) via the statistical package for the social sciences (SPSS) version 12.0 for Windows to compare the muscle activations at the different wheelchair tire pressures. When necessary, a post hoc Tukey HSD test was used to analyze the significant differences among the three different tire pressures. The level of significance was set at $\mathrm{p} \leq .05$.

\section{Results}

The muscle activities of the biceps brachii were 49.79 at $100 \mathrm{psi}, 73.80$ at $50 \mathrm{psi}$, and 74.77 at $30 \mathrm{psi}$; these measurements reveal significant differences between each pressure group $(\mathrm{p}<.05)$. The muscle activities of the triceps brachii were 33.82 at 100 psi, 49.00 at 50 psi, and 53.76 at $30 \mathrm{psi}$; these also revealed significant differences between the pressure groups $(\mathrm{p}<.05)$. The post hoc test found statistically significant differences between 100 psi and 50 psi and 100 psi and 25 psi for the biceps brachii and triceps brachii muscles, respectively $(\mathrm{p}<.05)$. (Table 1$)$.

\section{Discussion}

The purpose of this study was to investigate the effects of tire pressure, the only part of a wheelchair that touches the ground, on the biceps brachii and triceps brachii muscles during wheelchair propulsion.

Effective wheelchair propulsion is important for both caregivers and wheelchair occupants (Lee et al., 2013). Propulsion of a manual wheelchair is achieved via the muscle activities of the occupant; thus, studies are required to investigate effective methods for its propulsion.

The results of this study showed that tire pressure significantly affected muscle activities of the biceps brachii and triceps brachii during wheelchair propulsion. The muscles were less active at 100 psi than at 50 psi and 25 psi. The more the tire pressure decreased, the greater the area that came into contact with the ground, generating more friction against the ground (Thomas et al., 2014). Therefore, these results are considered to be due to the friction force increases by changes in the area touched with the ground because of decrease air pressure of the tire. Such an increase in friction may require more muscle activity in wheelchair propulsion. In this study, 50 psi tire pressure caused sufficient changes in muscle activity, the same pressure that has been reported as negatively affecting energy consumption and heart rate (Sawatzky et al., 2005).

This study was limited in that it observed only the elbow joints with three different levels of tire pressure. Further studies are needed to observe other joints and muscles during wheelchair propulsion using a variety of tire pressures on spinal cord injury patient.

Table 1. Comparison of wheelchair tire pressure on biceps brachii and triceps brachii

unit: \%MVIC

\begin{tabular}{cccccc}
\hline & $100 \mathrm{psi}$ & $50 \mathrm{psi}$ & $25 \mathrm{psi}$ & $\mathrm{F}$ & $p$ \\
\hline Biceps brachii & $49.79 \pm 6.77^{\mathrm{a}}$ & $73.80 \pm 4.29$ & $74.77 \pm 7.77$ & 51.27 & $.00^{*}$ \\
Triceps brachii & $33.82 \pm 6.68^{\mathrm{a}}$ & $49.00 \pm 8.40$ & $53.76 \pm 7.47$ & 17.38 & $.00^{*}$ \\
\hline
\end{tabular}

Mean $\pm \mathrm{SD}, *(\mathrm{p}<.05)$

NOTE. Each value represents the mean \pm SD. The values with different superscripts in the same column are different significantly $(\mathrm{p}<.05)$ by Tukey measure. 


\section{Conclusion}

Muscle activity is an important factor to consider when setting up a wheelchair for an individual. The decrease tire pressure by a superannuated tire increase muscle activity on upper limb muscle. The maintaining proper tire pressure in a wheelchair may help to prevent musculoskeletal injury in the occupant's elbow and shoulder joints.

\section{References}

Booka M, Yoneda I, Hashizume T, et al. Effect of tire pressure to physical workload at operating a manual wheelchair. Studies in Health Technology and Informatics. 2015;217:929-34

Chow JW, Millikan TA, Carlton LG, et al. Biomechanical comparison of two racing wheelchair propulsion techniques. Med Sci Sports Exerc. 2001;33:476-84.

de Groot S, Vegter RJ, van der Woude LH. Effect of wheelchair mass, tire type and tire pressure on physical strain and wheelchair propulsion technique. Med Eng Phys. 2013;35(10):1476-82.

Hong S, Lee H. An experimental study of tire safety and economical efficiency with respect to inflation pressure. Transactions of KSAE. 2010;18(1):8-13.

Lee SY. The Effect of Grip Strength in Change of Wrist Position according to Elbow Flexion. J Korean Soc Phys Med. 2009;4(4):209-14.

Lee SY, Kim SC, Lee MH, et al. Effect of the height of a wheelchair on the shoulder and forearm muscular activation during wheelchair propulsion. J Physi Ther Sci. 2012;24(1):51-3.

Lee SY, Kim SC, Lee MH, et al. Comparison of shoulder and back muscle activation in caregivers according to various handle heights. J Phys Ther Sci. 2013;25(10):1231-33.

Monahan T. Wheelchair athletes need special treatment but only for injuries. Physician Sports Med. 1986;14:121-8.

Thomas J, Huff S, West B. Fuel economy and emissions effects of low tire pressure, open windows, roof top and hitch-mounted cargo, and trailer. SAE Int J Passeng Cars. 2014;7(2):862-72.

Sawatzky BJ, Miller WC, Denison I. Measuring energy expenditure using heart rate to assess the effects of wheelchair tyre pressure. Clin Rehabil. 2005;19(2): 182-7. 